\title{
Voltage Sag Compensation of Point of Common Coupling (PCC) Using Fault Current Limiter
}

\author{
M. Jafari, Student Member, IEEE, S. B. Naderi, Student Member, IEEE, M. Tarafdar Hagh, Member, IEEE, S. H. Hosseini, \\ Member, IEEE, M. Abapour, Student Member, IEEE \\ Faculty of Electrical \& Computer Engineering, University of Tabriz, Tabriz, IRAN \\ Email: m.jafari87@ms.tabrizu.ac.ir
}

\begin{abstract}
In this paper, voltage sag compensation of point of common coupling (PCC) using a new structure of fault current limiter (FCL) is proposed. The proposed structure prevents voltage sag and phase angle jump of substation PCC after fault occurrence. This structure has a simple control method. Using semiconductor switch (IGBT or GTO) at dc current rout leads to fast operation of the proposed FCL and consequently, dc reactor value is reduced. On the other hand, the proposed structure reduces total harmonic distortion (THD) on load voltage and it has low ac losses in the normal operation. As a result, other feeders which are connected to the substation PCC will have good power quality. Analytical analysis, simulation results using PSCAD/EMTDC software and experimental results are presented to validate effectiveness of this structure.
\end{abstract}

Index Terms-Voltage sag, fault current limiter, power quality, point of common coupling (PCC), semiconductor switch, THD.

\section{INTRODUCTION}

Electric power quality can be defined as the capacity of an electric power system to supply electric energy of a load in an acceptable quality. Many problems can result from poor power quality, especially in today's complex power systems, such as false operation of modern control systems. Voltage sag is an important power quality problem because of sensitive loads growth. Worldwide experience shows that short circuit faults are the main origin of voltage sags and therefore the loss of voltage quality. This problem appears especially in buses which are connected to radial feeders [1-6].

The most common compensator for voltage sag is dynamic voltage restorer (DVR). The basic operation of the DVR is based on injection a compensation voltage with required magnitude, phase angle and frequency in series with sensitive electric distribution feeder [7,8].

The voltage sag during the fault is proportional to the short circuit current value. An effective approach to prevent expected voltage sag and improve the voltage quality of point of common coupling (PCC) is fault current limitation by means of a device connected at the beginning of most exposed radial feeders [9].

Superconducting fault current limiter (SFCL) structures have proper characteristics to control the fault current levels due to their variable impedance in the normal and fault conditions [10-13]. However, because of high technology and cost of superconductors, these devices are not commercially available. Therefore, by replacing the superconducting coil with nonsuperconducting one in the FCL, it is possible to make it simpler and much cheaper. It is important to note that, the main drawback of non-superconductor is a power loss which is negligible in comparison with the total power, provided by distribution feeder $[14,15]$.

The other structures which are introduced in [4, 16, 17], have two numbers of thyristor switches in AC branch of diode bridge. When the fault occurs, after fault detection, thyristor switch turns off at first zero crossing and the fault current is limited to an acceptable value. These structures have switching power loss and complicated control circuit because of thyristor switching in the normal operation. In addition, we know that thyristor operation delay (turn off at first zero crossing) makes interruption on structure performance. So, to limit the fault current between fault occurrence instant and thyristors turn off instant, a large reactor in dc route is used. Because of voltage drop, harmonic distortion and power losses, this large value of $\mathrm{dc}$ reactor is unfavorable.

In this paper a new topology of FCL is proposed for the voltage sag and the phase angle jump mitigation of the substation PCC. In section II, analytical analysis of voltage sag and phase angle jump is discussed. Then, in section III, the proposed FCL topology is introduced and its operation in a simplified power system is explained. In section $\mathrm{V}$, the PSCAD/EMTDC software is applied to investigate the operational behavior of the proposed FCL in this power system and simulation results are analyzed. Experimental results are presented and adapted with the simulations in section VI.

\section{Voltage Sag Study IN SimPlified POWER SyStem}

Fig. 1 shows single line diagram of the power system. This figure shows a substation with only two feeders F1 and F2. However, the presented analysis can be extended to any number of feeders, easily. The F1 supplies a sensitive load. With a fault in the F2, the voltage sag occurs in the substation PCC.

Positive sequence equivalent circuit of such a system is shown in Fig. 2. To calculate the voltage sag, the simple voltage divider method is introduced in [18].

In the normal state, the voltage magnitude and its phase angle in the substation PCC can be expressed as follows:

$$
\begin{gathered}
\bar{V}_{P C C(N)}=\frac{\bar{Z}_{K(N)}}{\left(\bar{Z}_{S}+\bar{Z}_{t}\right)+\bar{Z}_{K(N)}} \bar{V}_{s} \\
V_{P C C(N)}=\left|\frac{\bar{Z}_{K(N)}}{\left(\bar{Z}_{S}+\bar{Z}_{t}\right)+\bar{Z}_{K(N)}}\right|\left|\bar{V}_{s}\right| \\
\varphi_{P C C(N)}=\arctan \left(\frac{X_{K(N)}}{\left.R_{K(N)}\right)-\arctan \left(\frac{X_{K(N)}+X_{S}+X_{t}}{R_{K(N)}+R_{S}+R_{t}}\right)}\right.
\end{gathered}
$$




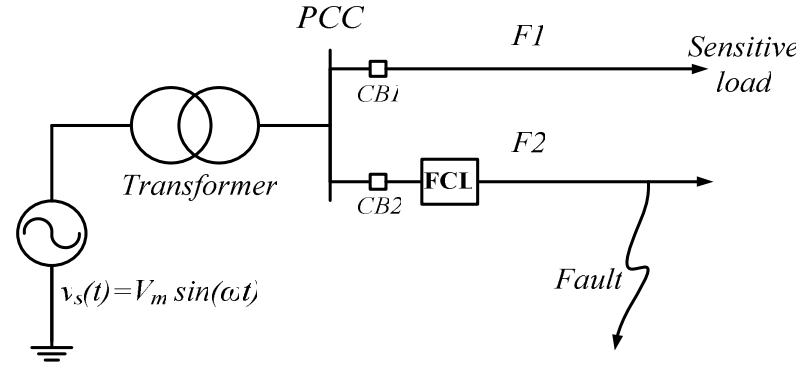

Fig. 1. Single line diagram of power system $P C C$

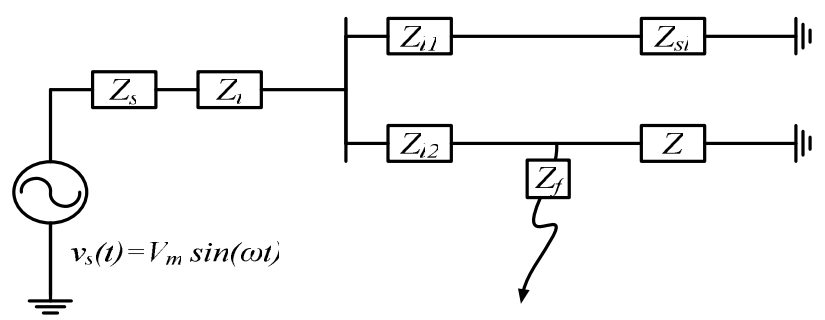

Fig. 2. Positive sequence equivalent circuit of the case study system in the fault where: condition

$\bar{V}_{P C C(N)}:$ Voltage phasor of PCC in the normal state;

$V_{P C C(N)}:$ Voltage magnitude of PCC in the normal state;

$\varphi_{P C C(N)}$ : Phase angle of PCC voltage in the normal state where, the phase angle of $\overline{V_{s}}$ is considered to be zero;

$\bar{Z}_{t}:$ Phasor of transformer impedance;

$\bar{Z}_{S}=R_{s}+j X_{s}:$ Phasor of source impedance;

$\bar{V}_{S}:$ Phasor of source voltage;

$\bar{Z}_{K(N)}=R_{K(N)}+j X_{K(N)}$ : Equivalent impedance of parallel feeders in the normal condition, i.e.:

$$
Z_{K(N)}=\left(\bar{Z}_{L 1}+\bar{Z}_{S L}\right) \|\left(\bar{Z}_{L 2}+\bar{Z}\right)
$$

$\bar{Z}$ : Phasor of load impedance at the $\mathrm{F} 2$.

In the normal state, $\left|\bar{Z}_{K(N)}\right|$ is greater than $\left|\bar{Z}_{S}+\bar{Z}_{t}\right|$. So, the PCC voltage is almost equal to the source voltage.

In the fault condition in the F2, the voltage and phase angle of substation PCC can be expressed as follows:

$$
\begin{gathered}
\bar{V}_{P C C(F)}=\frac{\bar{Z}_{K(F)}}{\left(\bar{Z}_{S}+\bar{Z}_{t}\right)+\bar{Z}_{K(F)}} \bar{V}_{s} \\
V_{P C C(F)}=\left|\frac{\bar{Z}_{K(F)}}{\left(\bar{Z}_{S}+\bar{Z}_{t}\right)+\bar{Z}_{K(F)} \mid}\right|\left|\bar{V}_{s}\right| \\
\varphi_{P C C(F)}=\arctan \left(\frac{X_{K(F)}}{R_{K(F)}}\right)-\arctan \left(\frac{X_{K(F)}+X_{S}+X_{t}}{R_{K(F)}+R_{S}+R_{t}}\right)
\end{gathered}
$$

where:

$\bar{V}_{P C C(F)}$ : Voltage phasor of PCC during fault;

$V_{P C C(F)}$ : Voltage magnitude of PCC during fault;

$\varphi_{P C C(F)}:$ Phase angle of voltage of PCC during fault;

$Z_{K(F)}=R_{K(F)}+j X_{K(F)}$ : Equivalent impedance of parallel feeders during fault, i.e.:

$$
\bar{Z}_{K(F)}=\left(\bar{Z}_{L 1}+\bar{Z}_{S L}\right) \|\left(\bar{Z}_{L 2}+\bar{Z}_{F}\right)
$$

$Z_{F}$ : Fault impedance.

In three phase fault condition (that is a balance fault.), $Z_{F}$ equals to zero approximately and according to Eq. (8), $\left|\bar{Z}_{K(F)}\right|$ will be small. Consequently, comparison of Eq. (2) with Eq. (6) and Eq. (3) with Eq. (7) show that the voltage sag and the phase angle jump occur in the fault interval, respectively. So, the sensitive load experiences worse condition. To prevent voltage sag and phase angle jump during fault, a proper solution is introducing a large limiting impedance between the substation PCC and the fault location. This solution is the base of FCL's operation.

\section{PROPOSED FCL CONFIGURATION AND ITS OPERATION}

Fig. 3 shows the circuit topology of the proposed FCL which is composed of two following parts:

1. Bridge part that includes a diode rectifier bridge, a small dc limiting reactor $\left(L_{d c}\right)$ (Note that, its resistance $\left(R_{d c}\right)$ is involved, too.), a semiconductor switch (IGBT or GTO), a free wheeling diode $\left(D_{5}\right)$.

2. Shunt branch as a compensator that consists of a resistor and an inductor $\left(R_{s h}+j \omega L_{s h}\right)$.

Previously introduced structures for this application $[4,16$, 17], have used two numbers of thyristors at bridge branches instead of one semiconductor switch inside the bridge (dc current route). Therefore, firstly, they have the more complicated control system. Secondly, in those structures, because of thyristors operation delay (turn off at first zero crossing), $L_{d c}$ has large value to limit the fault current between fault occurrence instant and thyristors turn off instant, properly. This large value of $L_{d c}$ leads to considerable voltage drop on the FCL and the power losses including ac power losses on the shunt branch impedance and dc reactor power losses (if it is non-superconductor) in the normal condition. By using the semiconductor switch in the proposed structure and its fast operation, it is possible to choose a small value for $L_{d c}$ to prevent sever $d i / d t$ at the beginning of fault occurrence. So, the voltage drop and power losses will be negligible. Nowadays, high rating semiconductor switches are available in practice. However, using self turn off switch instead of thyristors in the proposed structure leads to more cost [19-21]. From power loss point of view, in the normal condition, the proposed FCL has the losses on the rectifier bridge diodes, the semiconductor switch and $R_{d c}$. Each diode of the rectifier bridge is $\mathrm{ON}$ in half a cycle, while semiconductor switch is always ON. Therefore, the power losses of this FCL in the normal operation can be calculated as Eq. (9).

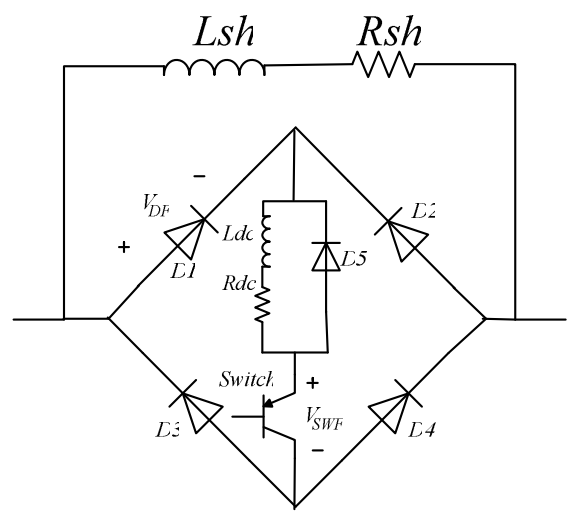

Fig. 3. The proposed FCL topology 


$$
P_{l o s s}=P_{R}+P_{D}+P_{S W}=R_{d c} I_{d c}^{2}+4 V_{D F} I_{a v e .}+V_{S W F} I_{d c}
$$

where:

$I_{d c}$ : dc side current which is equal to peak of line current

$\left(I_{\text {peak }}\right)$;

$V_{D F}$ : Forward voltage drop on each diode;

$V_{S W F}$ : Forward voltage drop on the semiconductor switch;

$I_{\text {ave. }}$ : Average of diodes current in each cycle that is equal to $I_{\text {peak }} / \pi$.

Considering Eq. (9) and the small value of dc reactor in this structure, total power losses of the proposed structure becomes a very small percentage of the feeder's transmitted power. For example, by considering Table I parameters in simulation section, the power losses will be $0.47 \%$ of the feeder's transmitted power.

On the other hand, in the fault condition, the PCC voltage drops on the shunt impedance. Therefore, the line current will pass through the shunt resistor $\left(R_{s h}\right)$. As a result, power loss on the $R_{s h}$ depends on its value that will be discussed in design considerations section. Note that the fault condition is several cycles and it is a small time interval.

\section{CONTROL Strategy}

Fig. 4 shows the control circuit of the proposed FCL. In the normal operation of the power system, the semiconductor switch is $\mathrm{ON}$ and the line current $\left(i_{L}\right)$ passes through " $D l, L_{d c}$, semiconductor switch, D4" and "D3, $L_{d c}$, semiconductor switch, D2" in positive and negative alternatives, respectively. So, $L_{d c}$ is charged to peak of the line current and behaves as a short circuit. Using semiconductor devices (diodes and semiconductor switch) and small dc reactor, cause a negligible voltage drop on the FCL.

When a fault occurs, $I_{d c}$ become greater than maximum permissible current $I_{m}$ and control circuit detects it and turns the semiconductor switch off. So, the bridge retreats from the feeder and the shunt impedance enters to the faulted line and limits the fault current. At this moment, the free wheeling diode discharges $L_{d c}$. In fact, the free wheeling diode is used to provide free route for $\mathrm{dc}$ reactor current when the semiconductor switch is OFF.

When fault is removed, while semiconductor switch is OFF, shunt impedance will be connected in series with the load impedance. Therefore, line current will be decreased, instantaneously. To detect this instantaneous reduction of line current, $i_{L}$ is compared with $\left(I_{f}\right)$ that can be calculated from Eq. (10).

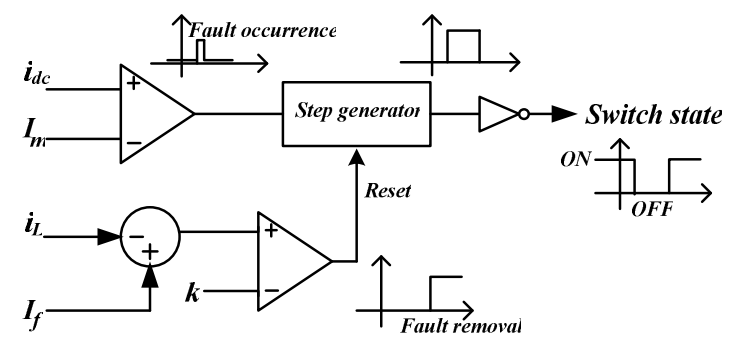

Fig. 4. Control circuit of the proposed FCL

$$
I_{f}=\frac{\left|\bar{V}_{P C C}\right|}{\left|R_{s h}+j \omega L_{s h}\right|}
$$

When the difference of $i_{L}$ and $I_{f}$ become greater than $\mathrm{k}$ as the fault removal sign, control circuit turns the semiconductor switch ON. So, power system returns to the normal state. The value of $k$ can be calculated from Eq (11) as follow:

$$
k=\frac{\left|\bar{V}_{P C C}\right|}{\left|\bar{Z}_{s h}\right|}-\frac{\left|\bar{V}_{P C C}\right|}{\left|\bar{Z}_{s h}+\bar{Z}_{L, \text { min }}\right|}
$$

where:

$Z_{s h}:$ The shunt impedance;

$Z_{L, \text { min }}$ : Minimum impedance of load on the protected feeder.

\section{DESIGN CONSIDERATIONS}

As mentioned previously, $L_{d c}$ is placed in series with the semiconductor switch to protect it against severe $d i / d t$ at the beginning of fault occurrence. So, its value can be chosen considering current characteristic of the semiconductor switch.

For designing shunt branch parameters, it is possible to consider following conditions. In the ideal case, shunt branch impedance is equal to load impedance. In this condition, when a fault happens in the protected feeder, the voltage sag at the PCC will be zero. However, it is difficult to equate these impedances exactly because of load variation on distribution feeders. So, it is difficult to estimate the best value for $L_{s h}$ and $R_{s h}$. From practical point of view, parameters of shunt branch can be determined by using the history of load measurements at the protected feeder. It is obvious that feeder's power and consequently its current change. For calculation of $L_{s h}$ and $R_{s h}$ values, average impedance of the protected feeder is calculated. So, $L_{s h}$ and $R_{s h}$ are chosen equal to its inductance and resistance.

From practical point of view, Fig 5(a) and Fig. 5(b) are considered. Fig. 5(a) shows the magnitude of PCC voltage. The horizontal axis of this figure shows the magnitude of load impedance in per-unit where the base value is its impedance of ideal case. The dashed line shows the existence of ideal case. The ratio of reactance to resistance of shunt branch is kept constant in this figure. The parameter of this figure is the magnitude of source impedance. This figure shows that for a wide range of load magnitude variations ( 0.5 to 2 p.u. with fixed shunt branch impedance), the voltage magnitude of PCC for post-fault condition changes in an acceptable range especially for low values of $\left|\bar{Z}_{S}\right|$.

Fig. 5(b) shows the phase angle deviation of the PCC from its base value that is the phase angle deviation of pre-fault PCC voltage. The horizontal axis of this figure is the ratio of reactance to resistance of shunt branch in per-unit where the base value is obtained from ideal condition. This figure shows that it is possible to decrease the resistance of shunt branch (without changing the magnitude of its impedance) in a wide range without any considerable phase angle jump during fault. Decreasing $R_{s h}$ decreases the power loss of shunt branch during short circuit interval. So, its design becomes simpler. 


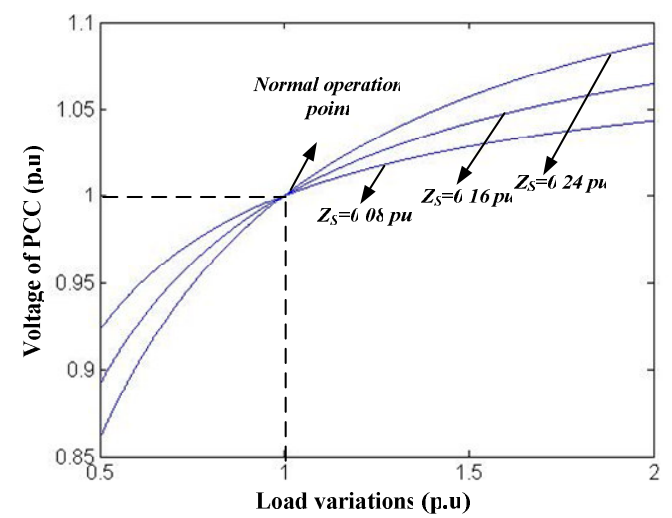

(a)

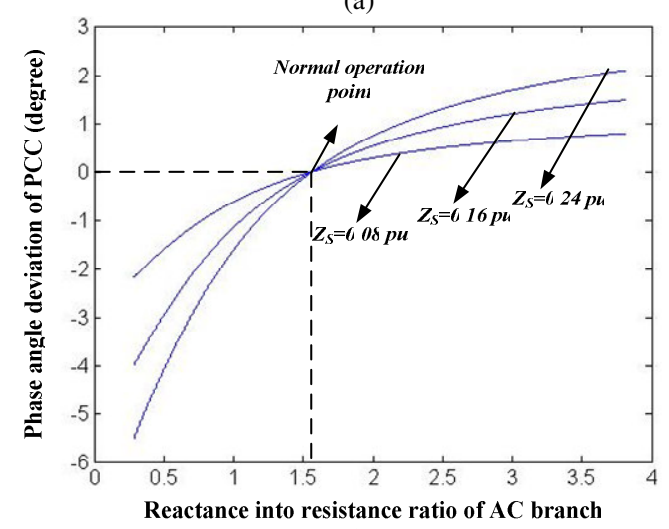

(b)

Fig. 5. (a) Voltage magnitude and (b) Phase angle deviation of the PCC when shunt branch impedance is not equal to the protected feeder load impedance (non-ideal case).

\section{Simulation Results And EFFECT OF the PROPOSED FCL on Voltage SAG AND Phase ANGLE JuMP}

With a balanced fault at the F2 in Fig. 1, without using the FCL, the PCC voltage drops, severely. When the FCL is installed in the F2, not only reduces the fault current, but also restores the non-faulted feeder voltage to the normal level. So, the FCL improves the voltage quality and the reliability of the supply network. In this section, analytical analysis of the proposed FCL and simulation results are presented. System parameters are as Table I. These simulations are obtained using the PSCAD/EMTDC software. In addition, considering section IV, to show the practical condition, the values of shunt branch parameters $\left(R_{s h}, L_{s h}\right)$ are the non-ideal case.

\begin{tabular}{|c|c|l|}
\multicolumn{2}{c}{ Table I. System parameters } \\
\hline \multirow{3}{*}{ Source Side Data } & Power source & $\begin{array}{l}20 \mathrm{kV}, 50 \mathrm{~Hz}, \mathrm{X} / \mathrm{R} \text { ratio: } 5 \\
\text { Total Impedance: } 1.608 \Omega\end{array}$ \\
\cline { 2 - 3 } & Transformer & $20 \mathrm{kV} / 6.6 \mathrm{kV}, 10 \mathrm{MVA}, 0.1 \mathrm{pu}$ \\
\hline \multirow{2}{*}{$\begin{array}{c}\text { Distribution } \\
\text { feeders data }\end{array}$} & Feeder F1 & $\mathrm{j} 0.314 \Omega$ \\
\cline { 2 - 3 } & Feeder $\mathrm{F} 2$ & $\mathrm{j} 0.157 \Omega$ \\
\hline \multirow{3}{*}{ FCL data } & dc side & $\begin{array}{l}L_{d c}=0.01 \mathrm{H}, R_{d c}=0.03 \Omega \\
V_{D F}=3 V, V_{S W F}=3 V, I_{m}=0.6 \mathrm{kA} \\
\text { Switch type: IGBT }\end{array}$ \\
\hline \multirow{2}{*}{ Load data } & Shunt branch & $L_{s h}=0.08 \mathrm{H}, R_{s h}=5 \Omega$ \\
\cline { 2 - 3 } & Sensitive load & $10+\mathrm{j} 15.7 \Omega$ \\
\cline { 2 - 3 } & Load of F2 & $15+\mathrm{j} 31.4 \Omega$ \\
\hline
\end{tabular}

As shown in Fig. 6, in the fault condition (fault occurs at $t_{0}=1 s$ ), the PCC voltage and power transfer to the sensitive load drop without the FCL. Considering this figure, it shows that zero crossing of the PCC voltage changes before and after fault. With placing the proposed FCL in outset of the F2, when the fault happens, the proposed FCL inserts large impedance into the faulted line and prevents the voltage sag and phase angle jump at the substation PCC. Fig. 7 shows the PCC voltage and sensitive load single phase power in this condition. In the first moments of fault, slight distortion appears in the PCC voltage waveform caused by the semiconductor switch operation and inserting the shunt impedance into the faulted line. After that, the PCC voltage sag and phase angle jump will be in an acceptable range that is discussed in section IV in detail. The power of the sensitive load in this interval has not any considerable change.

In comparison with operation of the structures introduced in [4], [16] and [17], using the semiconductor switch at dc current route in the proposed FCL instead of thyristors at bridge branches, leads to mitigation of sag and distortion in the PCC voltage after fault occurrence (Fig. 8). As shown in simulation results, the proposed FCL can resolve voltage sag and phase angle jump problem properly.

Fig. 9 shows the voltage drop on the proposed FCL during fault. This voltage drop causes that the PCC voltage does not change (considering Fig. 7(a)).

Fig. 10 shows the line current of F2, dc reactor and shunt impedance current $\left(i_{L}(t), i_{d c}(t)\right.$ and $i_{s h}(t)$ respectively). As shown in Fig. 10(b), between fault occurrence instant $\left(t_{0}\right)$ and line current rising to its normal condition's peak instant $\left(t_{1}\right)$, the dc reactor current does not change. From instant $t_{1}$ to $t_{2}$ (semiconductor switch operation instant), the dc reactor charges according to differential Eq. (12).

$$
\left\{\begin{array}{l}
\omega L_{d c} \frac{d i_{d c}(\omega t)}{d \omega t}+R_{d c} i_{d c}(\omega t)+2 V_{D F}+V_{S W F}=V_{P C C} \\
i_{d c}\left(\omega t=\omega t_{1}\right)=I_{\text {peak }}
\end{array}\right.
$$

where:

$i_{d c}(\omega t): \mathrm{dc}$ reactor current between $t_{1}$ to $t_{2}$;

$V_{P C C}=V_{P} \sin (\omega t)$.

Solution of Eq. (13) leads to:

$$
i_{d c}(\omega t)=A e^{\frac{-R_{d c}}{\omega L_{d c}} \omega\left(t-t_{1}\right)}+B \sin \left(\omega t-\varphi_{d c}\right)+K
$$

where:

$$
\left\{\begin{array}{l}
A=I_{d c}-\frac{V_{P}}{\sqrt{R_{d c}^{2}+\omega^{2} L_{d c}^{2}}} \sin \left(\omega t_{1}-\varphi_{d c}\right)+\frac{2 V_{D F}+V_{S W F}}{R_{d c}} \\
B=\frac{V_{P}}{\sqrt{R_{d c}^{2}+\omega^{2} L_{d c}^{2}}} \\
K=-\frac{2 V_{D F}+V_{S W F}}{R_{d c}} \\
\varphi_{d c}=\arctan \left(\frac{\omega L_{d c}}{R_{d c}}\right)
\end{array}\right.
$$




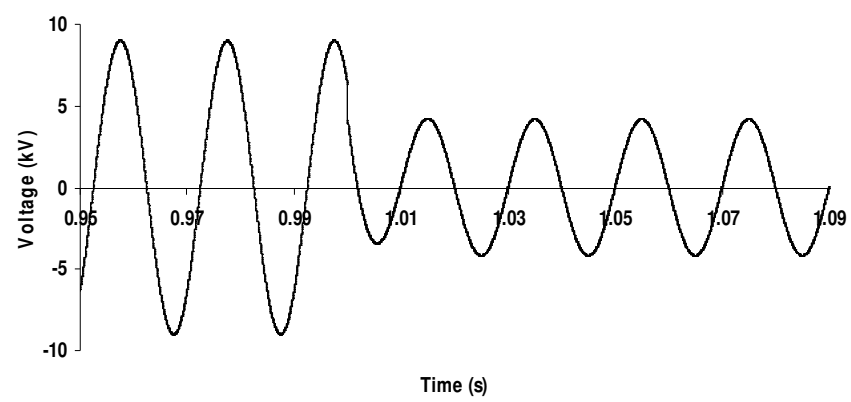

(a)

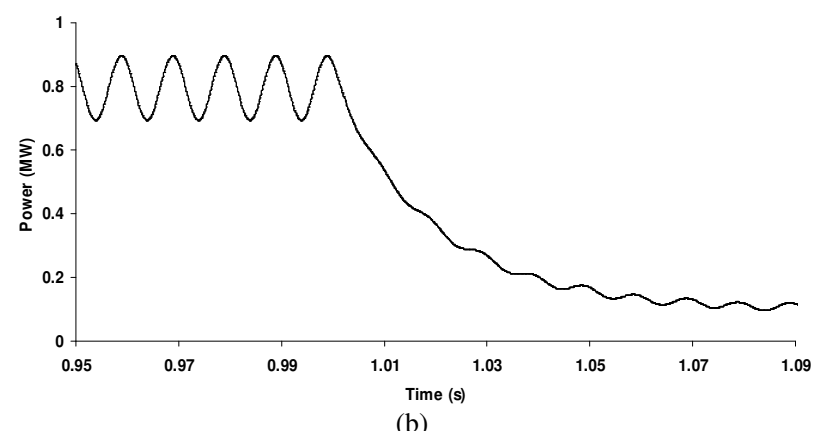

Fig. 6. (a) PCC voltage and (b) Single phase instantaneous power of the sensitive load without FCL

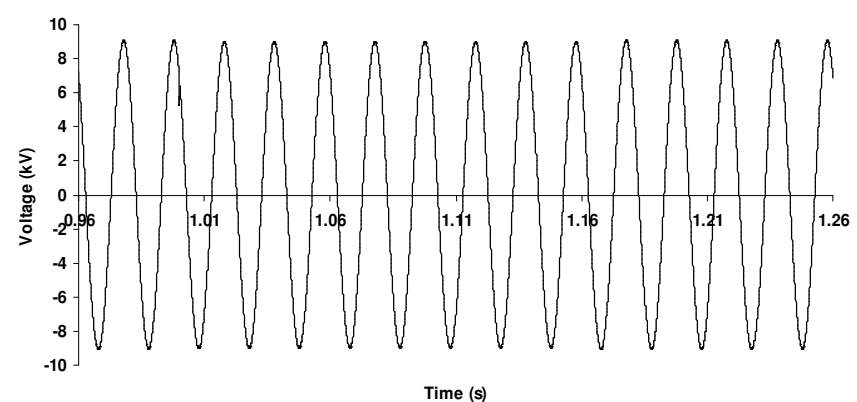

(a)

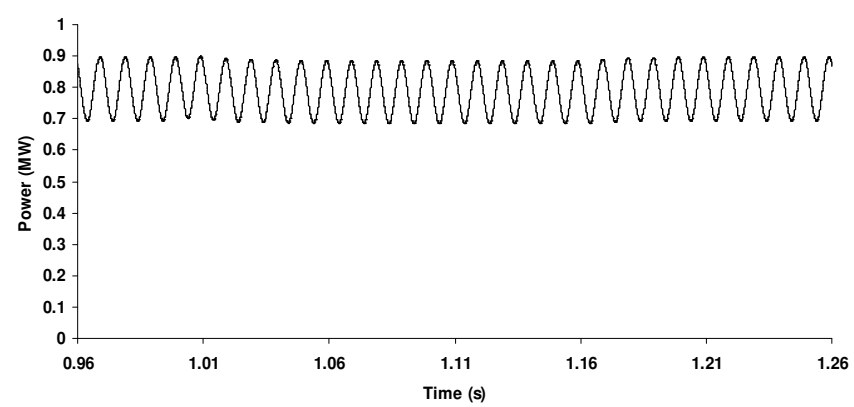

(b)

Fig. 7. (a) PCC voltage and (b) Single phase instantaneous power of the

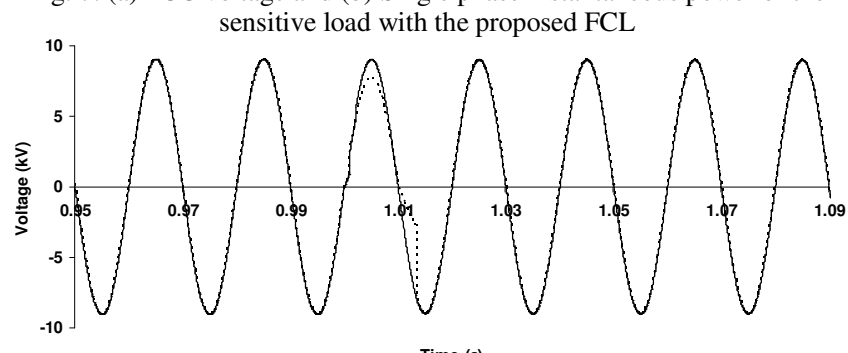

Time (s)

.... PCC voltage with Thyristor switch in pervious structures PCC voltage with the proposed structure

(a)

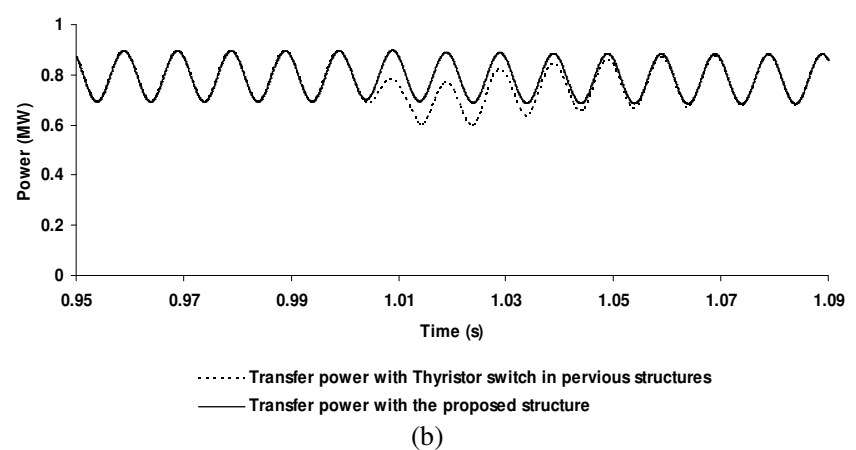

Fig. 8. (a) PCC voltage and (b) Single phase instantaneous power of the sensitive load waveforms with semiconductor switch in the proposed FCL and thyristor switches in previously structures

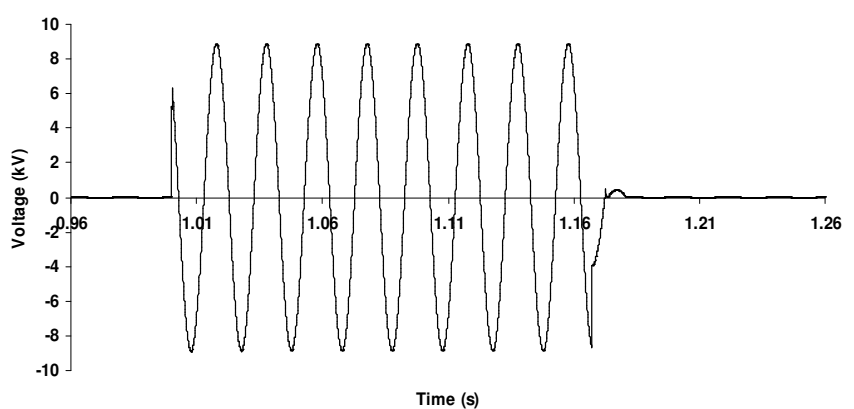

Fig. 9. Voltage drop on the proposed FCL during fault

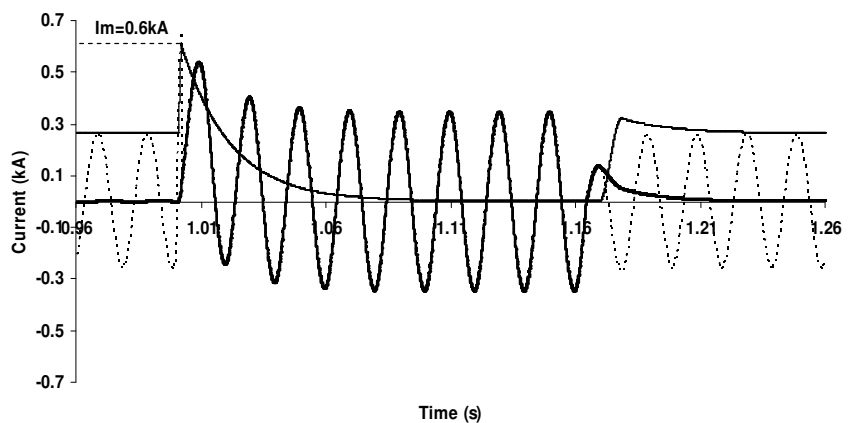

(a)

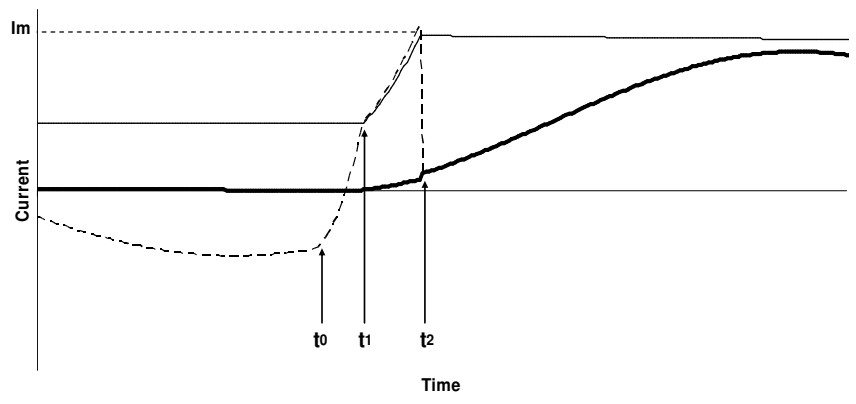

(b)

Fig. 10. (a) Line, dc reactor and shunt impedance currents and (b) enlarged view

In addition, at this interval, voltage across the proposed FCL increases shunt impedance current. Differential equation of this current is expressed by Eq. (15):

$$
\omega L_{s h} \frac{d i_{s h}(\omega t)}{d \omega t}+R_{s h} i_{s h}(\omega t)=V_{P C C}
$$


Initial value of $i_{s h}(\omega t)$ is zero. So:

$$
i_{s h}(\omega t)=A e^{\frac{-R_{s h}}{\omega L_{s h}} \omega\left(t-t_{1}\right)}+B \sin \left(\omega t-\varphi_{s h}\right)
$$

where:

$$
\left\{\begin{array}{l}
A=-\frac{V_{P}}{\sqrt{R_{s h}^{2}+\omega^{2} L_{s h}^{2}}} \sin \left(\omega t_{1}-\varphi_{s h}\right) \\
B=\frac{V_{P}}{\sqrt{R_{s h}^{2}+\omega^{2} L_{s h}^{2}}} \\
\varphi_{s h}=\arctan \left(\frac{\omega L_{s h}}{R_{s h}}\right)
\end{array}\right.
$$

Note that the time interval between $t_{1}$ to $t_{2}$ is some milliseconds.

Semiconductor switch control strategy is based on maximum permissible fault current, $I_{m}$. Between $t_{1}$ to $t_{2}$, line current $\left(i_{L}(\omega t)\right)$ equals to $i_{d c}(\omega t)$ plus $i_{s h}(\omega t)$ (Fig. 10(b)). When semiconductor switch current exceeds $I_{m}$, control system of its turns it off. In Eq. (13), if $i_{d c}(\omega t)$ is equal to $I_{m}$, semiconductor switch operation instant $\left(t_{2}\right)$ can be calculated. After $t_{2}$, the diode bridge retreats and the shunt impedance limits the fault current. Until fault clearance instant and turning on the semiconductor switch, the line current follows Eq. (16). In addition, at this interval, $i_{d c}(\omega t)$ is discharged by $D_{5}$ as following equation:

$$
\left\{\begin{array}{l}
\omega L_{d c} \frac{d i_{d c}(\omega t)}{d \omega t}+R_{d c} i_{d c}(\omega t)=0 \\
i_{d c}\left(\omega t=\omega t_{2}\right)=I_{m}
\end{array}\right.
$$

As a result:

$$
i_{d c}(\omega t)=I_{m} e^{\frac{-R_{d c}}{\omega L_{d c}} \omega\left(t-t_{2}\right)}
$$

It is important to note that Eq. (16) is composed of two parts, exponential and sinusoidal. The Exponential part causes a transient in the line current (as shown in Fig. 10(a)) that duration of this transient depends on time constant of the shunt impedance $\left(L_{s h} / R_{s h}\right)$.

\section{EXPERIMENTAL SETUP}

To show effectiveness of the proposed FCL, an experimental setup is provided and its results are shown in this section. Table II shows parameters of the experimental study.

Fig. 11 shows the PCC voltage in a balanced fault condition by using the proposed FCL. This figure is in agreement with Fig. 7(a). It is obvious that the proposed FCL prevents the voltage sag with negligible distortion only because of semiconductor switch operation. In addition, the phase angle jump on the PCC voltage is mitigated, too

The voltage drop on the FCL is shown in Fig. 12. It is obvious that this figure follows Fig. 9. Fig. 13(a) and 13(b) show the line current of the F2 and the shunt impedance current, respectively. In general, the experimental setup validates the simulation results and shows that the proposed FCL has acceptable capabilities for the voltage quality improvement and the current limiting aims.
Table II. Experimental setup parameters

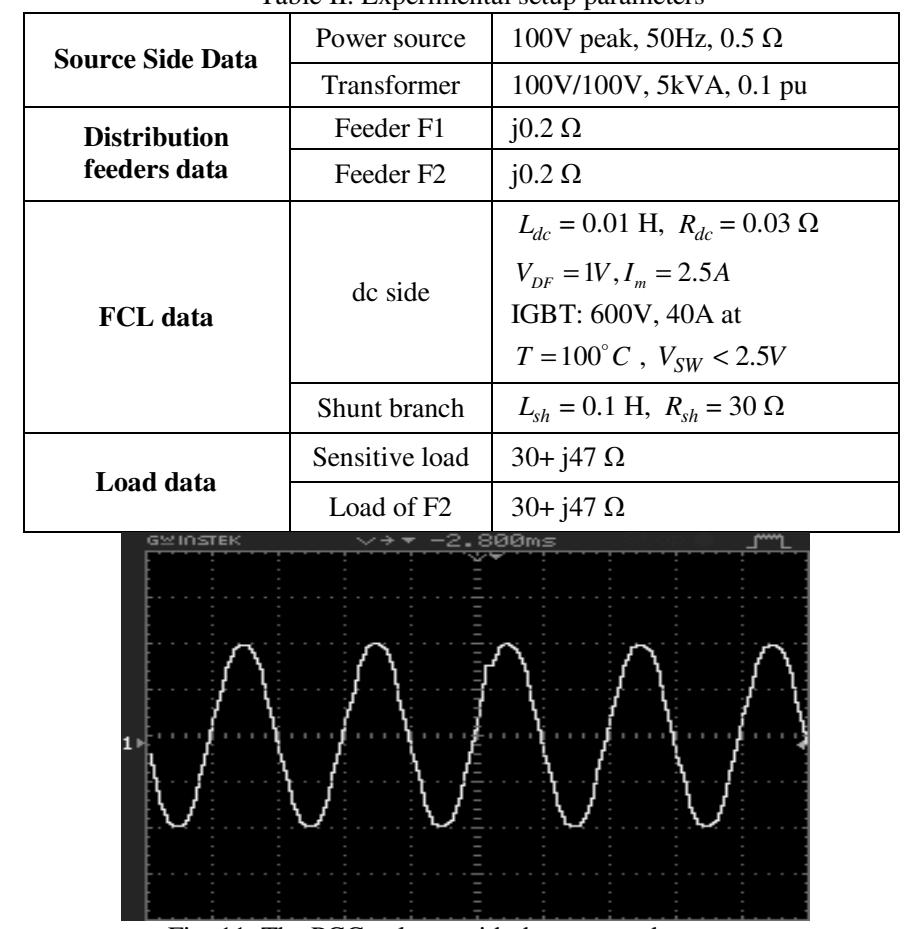

Fig. 11. The PCC voltage with the proposed structure (Volt/div.: 50V, Time/div.: 10ms)

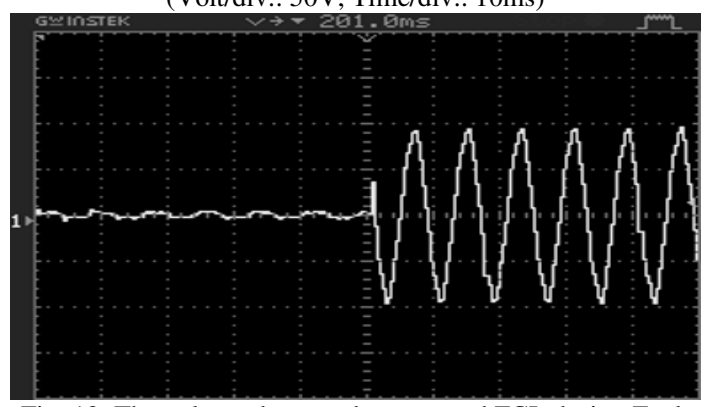

Fig. 12. The voltage drop on the proposed FCL during Fault (Volt/div.: 50V, Time/div.: 25ms)

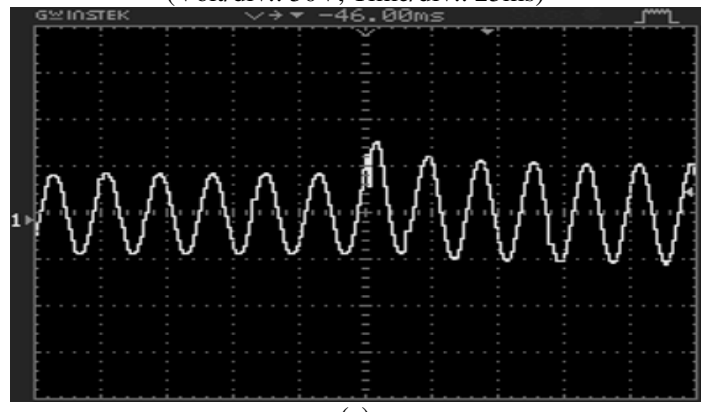

(a)

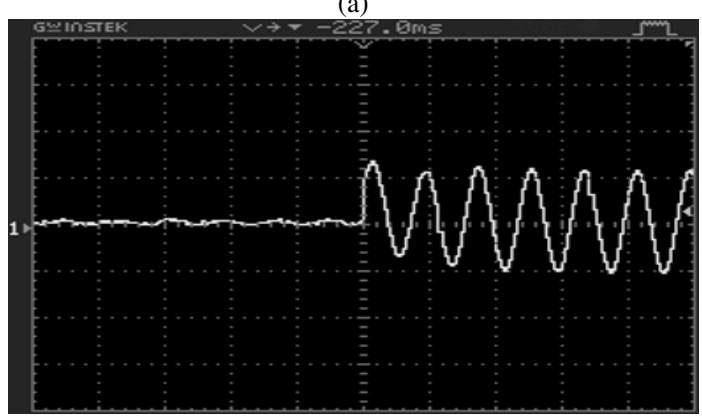

(b)

Fig. 13. (a) Line current of the F2, (b) Shunt impedance current (Current/div.: 2A, Time/div.: 25ms) 


\section{HARMONIC STUDY}

As mentioned above, because of using the diodes, the semiconductor switch and the small dc reactor, there is a voltage drop on the FCL. This voltage drop causes harmonic distortion on load voltage and power losses in shunt branch in normal condition.

Using dc voltage source in the proposed structure, Fig. 14, compensates voltage drop on the power electronic devices and the small dc reactor resistance. So, it reduces total harmonic distortion (THD) of voltage waveform [14, 22, and 23]. Its magnitude can be achieved by Eq. (20) as follow:

$$
V_{d c}=R_{d c} I_{d c}+2 V_{D F}+V_{S W F}
$$

Where, $V_{S W F}$ and $V_{D F}$ stand for the voltage drops across the semiconductor switch and each diode, respectively. $I_{d c}$ is the current of $\mathrm{dc}$ route that is equal to the peak of line current in the normal condition. It is important to note that the dc voltage source can be simply provided by a rectifier $[14,15]$.

Fig. 15 shows load voltage in the normal operation of the power system with and without the dc voltage source and Fig. 16 shows frequency spectrum of the load voltage. By using the dc voltage source, the distortions of voltage waveform decreases to lower values in the normal condition, as shown in Fig. 14 and Fig. 16. THD of the load voltage in case of the proposed FCL without and with the dc voltage source are $2.789 \%$ and $0.117 \%$, respectively.

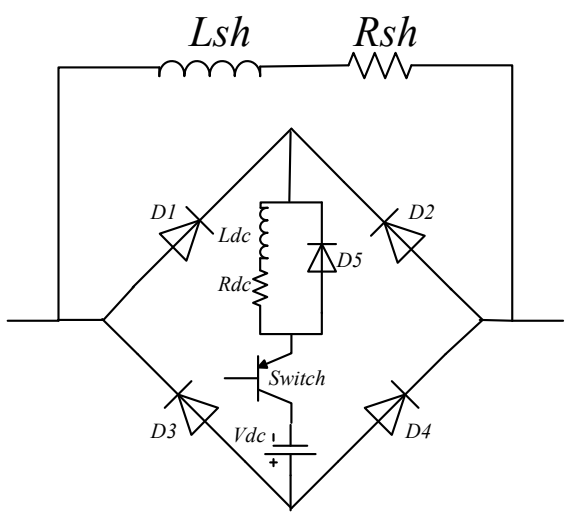

Fig. 14. The proposed FCL topology with dc voltage source

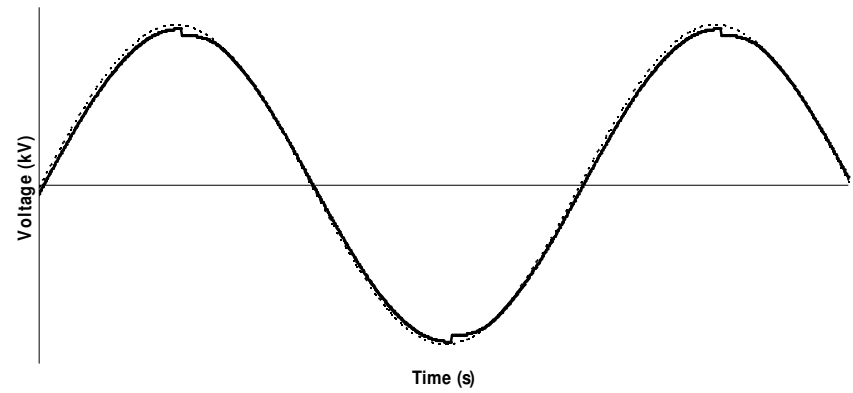

... Load voltage with dc voltage source __L Load voltage without dc voltage source

Fig. 15. The load voltage in the normal operation of the power system with and without the dc voltage source
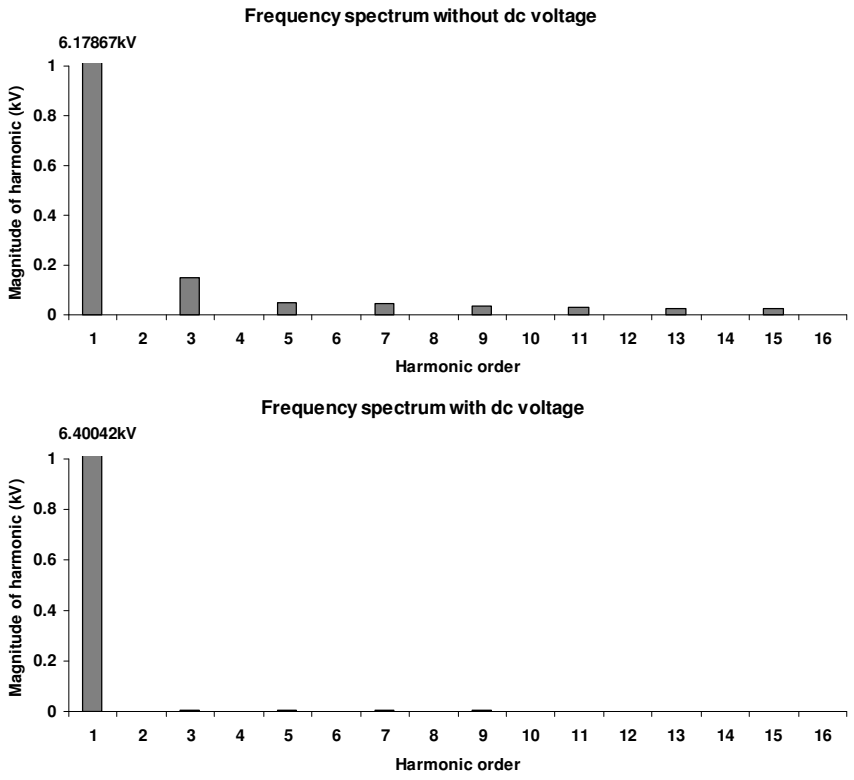

Fig. 16. Frequency spectrum of the load voltage

\section{CONCLUSION}

In this paper, the proposed FCL structure is introduced. Voltage sag compensation, phase angle jump mitigation and fault current limiting operation due to the control method were analyzed. The computer simulation using the PSCAD/EMTDC software and the experimental study are presented to validate results of the analytical analysis. The proposed FCL is capable of mitigating voltage sag and phase angle jump to acceptable levels. Because of using the semiconductor switch in dc current path instead of two numbers of thyristor at the bridge branches, the proposed FCL has high speed and consequently, dc reactor value is reduced to lower value. Note that the control system of this structure is simpler than previous ones. In addition, the dc voltage source placed in the proposed FCL structure reduces its THD and ac losses in the normal operation. In general, this type of FCL with the simple control circuit and low cost is useful for the voltage quality improvement because of voltage sag and phase angle jump mitigating and low harmonic distortion in distribution systems.

\section{REFERENCES}

[1] Jovica V. Milanovic, Yan Zhang, "Modeling of FACTS Devices for Voltage Sag Mitigation Studies in Large Power Systems," IEEE Trans. Power Del., vol. 25, no. 4, pp. 3044-3052, Oct 2010.

[2] Timothy J. Browne, Gerald T. Heydt. "Power Quality as an Educational Opportunity," IEEE Trans. Power Del., vol. 23, no. 2, pp. 814-815, May 2008.

[3] Nesimi Ertugrul, Ameen M. Gargoom, Wen. L. Soong. "Automatic Classification and Characterization of Power Quality Events," IEEE Trans. Power Del., vol. 23, no. 4, pp. 2417-2425, Oct 2008.

[4] M. Abapour, Seyed Hossein Hosseini, M. Tarafdar Hagh. "Power Quality Improvement by Use of a New Topology of Fault Current Limiter," ECTI-CON. , pp. 305-308, 2007.

[5] Morris Brenna, Roberto Faranda, Enrico Tironi. "A New Proposal for Power Quality and Custom Power Improvement: OPEN UPQC," IEEE Trans. Power Del., vol. 24, no. 4, pp. 2107-2116, Oct 2009.

[6] WanMin Fei, YanLi Zhang, ZhengYu Lü, "Novel Bridge-Type FCL Based on Self-Turnoff Devices for Three-Phase Power Systems," IEEE Trans. Power Del., vol. 23, no. 4, pp. 2068-2078, Oct 2008.

[7] E. Babaei, M. Farhadi Kangarlu, M. Sabahi, "Mitigation of Voltage Disturbances Using Dynamic Voltage Restorer Based on Direct 
Converters," IEEE Trans. Power Del., vol. 25, no. 4, pp. 2676-2683, Oct 2010.

[8] Majid Moradlou, Hamid R. Karshenas, "Design Strategy for Optimum RatingSelection of Interline DVR," IEEE Trans. Power Del., vol. 26, no. 6, pp. 242-249, Jan. 2011.

[9] Stefano Quaia, Fabio Tosato. "Reducing Voltage Sags Through Fault Current Limitation," IEEE Trans. Power Del., vol. 16, no. 1, pp. 12-17, Jan 2001.

[10] Lei Chen, Yuejin Tang, Zhi Li, Li Ren, Jing Shi, Shijie Cheng. "Current Limiting Characteristics of a Novel Flux-Coupling Type Superconducting Fault Current Limiter," IEEE Trans. Appl. Supercond., vol. 20, no. 3, pp. 1143-1146, June 2010.

[11] Y. Cai, S. Okuda, T. Odake, T. Yagai, M. Tsuda, T. Hamajima. "Study on Three-Phase Superconducting Fault Current Limiter," IEEE Trans. Appl. Supercond., vol. 20, no. 3, pp. 1127-1130, June 2010.

[12] S. B. Abbott, D. A. Robinson, S. Perera, F. A. Darmann, C. J. Hawley, and T. P. Beales. "Simulation of HTS Saturable Core-Type FCLs for MV Distribution Systems," IEEE Trans. Power Del., vol. 21, no. 2, pp. 10131018, April 2006

[13] Koki Omura, Hiroki Kojima, Naoki Hayakawa, Fumihiro Endo, Mathias Noe, Hitoshi Okubo. "Current Limiting Characteristics of ParallelConnected Coated Conductors for High-Tc Superconducting Fault Current Limiting Transformer (HTc-SFCLT)," IEEE Trans. Appl. Supercond., vol. 19, no. 3, pp. 1880-1883, June 2009.

[14] Mehdi Abapour, Mehrdad Tarafdar Hagh. "Nonsuperconducting Fault Current Limiter With Controlling the Magnitudes of Fault Currents," IEEE Trans. Power Elect., vol. 24, no. 3, pp. 613-619, March 2009.

[15] M. Tarafdar Hagh, M. Abapour. "Non-superconducting fault current limiters," Euro. Trans. Elect. Power, vol. 19, Issue 5, pp. 669-682, July 2009.

[16] D. Jiang, Z. Lu, Z. Wu. "A new topology of fault-current limiter and its parameters optimization," Proc. IEEE Power Electron. Specialists Conf., pp. 462-465, June 2003.

[17] J. Daozhuo, C. Gang, C. Yonghua, "Study on a novel solid state fault current limiter with bypass reactor," Proc. Chinese Soc. Electrical Eng, pp. 200-205, Jul 2004.

[18] L.E. Conrad. "Proposed Chapter 9 for predicting voltage sags (Dips) in revision to IEEE Std. 493, the gold book," IEEE Trans. on Ind. Application, vol. 30, no. 3, pp. 805-821, May/June 1994.

[19] The Engineering Search Engine, Globalspec Inc., www.globalspec.com.

[20] B. Abdi, A. H. Ranjbar, G. B. Gharehpetian and J. Milimonfared, "Reliability considerations for parallel performance of semiconductor switches in high-power switching power supplies," IEEE Trans., Ind. Electron., vol. 56, no. 6, pp. 2133-2139, Jun. 2009.

[21] X. He, A. Chen, H. Wu, Y. Deng and R. Zhao, "Simple passive lossless snubber for high-power multilevel inverters," IEEE Trans., Ind. Electron., vol. 53, no. 3, pp. 727-735, Jun. 2006.

[22] Seungje Lee, Chanjoo Lee, Min Cheol Ahn, Hyoungku Kang, Duck Kweon Bae, and Tae Kuk Ko, "Design and Test of Modified Bridge Type Superconducting Fault Current Limiter With Reverse Magnetized Core,” IEEE Trans. Appl. Supercond., vol. 13, no. 2, pp. 2016-2019, June 2003.

[23] Toshifumi Ise, Nguyen Hong Nguyen, and Sadatoshi Kumagai, "Reduction of Inductance and Current Rating of the Coil and Enhancement of Fault Current Limiting Capability of a Rectifier Type Superconducting Fault Current Limiter," IEEE Trans. Appl. Supercond., vol. 11, no. 1, pp. 1932-1935, March 2001.

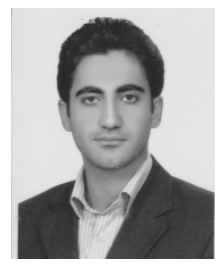

Mehdi Jafari (S'10) was born in Ahar, Iran in 1986. He received the B.S. and M.Sc. degrees in power engineering from the University of Tabriz, Tabriz, Iran, in 2008 and 2011, respectively. His current research interests include fault current limiters, power quality and power system transient.

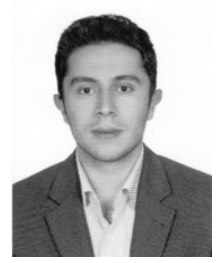

Seyed Behzad Naderi (S'10) was born in Sarab, Iran in 1986. He received the B.S. and M.Sc. degrees in power engineering from the University of Tabriz, Tabriz, Iran, in 2008 and 2011, respectively. His current research interests include fault current limiters, power system transient and power quality.

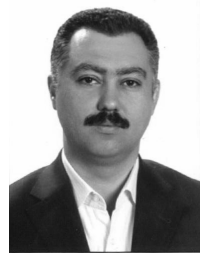

Mehrdad Tarafdar Hagh (S'98-M'06) received his M. Sc with first honor and $\mathrm{Ph}$. D. both in power engineering from University of Tabriz, Iran in 1992 and 2000, respectively. He has been with the faculty of electrical and computer engineering, University of Tabriz from 2000, where he is currently an Associate Professor. He has published more than 150 papers in power system and power electronics related topics. His interest topics include power system operation, FACTS and power quality.

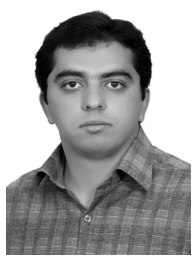

Mehdi Abapour (S'09) received the B.S. and M.Sc. degrees in power engineering from the University of Tabriz, Tabriz, Iran, in 2005 and 2008, respectively. He is currently working toward the Ph.D. degree at Tarbiat Modares University, Tehran, Iran. His current research interests include fault current limiters, reliability and power system operation.

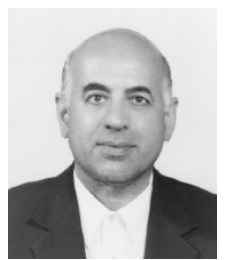

Seyed Hossein Hosseini (M'93) was born in Marand, Iran in 1953. He received the M.S. degree from the Faculty of Engineering University of Tabriz, Iran in 1976, the DEA degree from INPL, France, in 1978 and Ph.D. degree from INPL, France, in 1981 all in electrical engineering. In 1982 he joined the University of Tabriz, Iran, as an assistant professor in the Dept. of Elec. Eng., from 1990 to 1995 he was associate professor in the University of Tabriz, since 1995 he has been professor in the Dept. of Elec. Eng. University of Tabriz. From Sept. 1990 to Sept. 1991 he was visiting professor in the University of Queensland, Australia; from Sept. 1996 to Sept. 1997 he was visiting professor in the University of Western Ontario, Canada. His research interests include Power Electronic Converters, Matrix Converters, Active \& Hybrid Filters, Application of Power Electronics in Renewable Energy Systems and Electrified Railway Systems, Reactive Power Control, Harmonics and Power Quality Compensation Systems such as SVC, UPQC, FACTS devices. 